\title{
Dinâmica reprodutiva de Oligosarcus jenynsii e $O$. robustus (Characiformes, Characidae) na Lagoa Fortaleza, Rio Grande do Sul, Brasil
}

\author{
Daniela M. Nunes ${ }^{1}$; Mateus Pellanda ${ }^{2} \&$ Sandra Maria Hartz ${ }^{1}$ \\ 1. Pós-Graduação em Ecologia, Universidade Federal do Rio Grande do Sul, Av. Bento Gonçalves, 9500, Caixa Postal 15007, \\ 91501-970, Porto Alegre, RS, Brasil. \\ 2. Bolsista de IC PROPESQ/UFRGS.
}

\begin{abstract}
Reproductive dynamics of Oligosarcus jenynsii and O. robustus (Characiformes, Characidae) in Fortaleza Lagoon, Rio Grande do Sul, Brazil. Oligosarcus jenynsii (Günther, 1864) and O. robustus Menezes, 1969 are fish species distributed in Rio Grande do Sul, Brazil, Uruguay, and northern Argentina. The reproductive period and recruitment, sex ratio, absolute and relative fecundity, and body length at first gonadal maturation of the two carnivorous species from Fortaleza Lagoon were analized. The specimens were sampled monthly, from May 2000 to April 2001, with fishing effort of 24 hours/month, using stationary gillnets of different mesh sizes and seine net (three samples per edge). The records of each individual included total length, total weight, gonad weight, sex and gonadal maturity stage. The reproductive period of both $O$. jenynsii and $O$. robustus ranges from May/June to November/ December, according to the bimonthly variation of the mean values of gonosomatic index, and the relative frequencies of the gonadal maturation stages. Recruitment of new individuals to the population occurs from November/December to March/April. The sex ratio is different from 1:1 for O. jenynsii and similar to 1:1 for O. robustus. The mean absolute fecundity, calculated by counting sub-sampled oocytes from mature females, was 14,483 oocytes for $O$. jenynsii, and 16,308 oocytes for $O$. robustus. The first maturation curve shows that $O$. jenynsii begins to reproduce between $84 \mathrm{~mm}$ and $104 \mathrm{~mm}$ (total length), and $O$. robustus between $126 \mathrm{~mm}$ and $146 \mathrm{~mm}$, probably at similar ages.
\end{abstract}

KEYWORDS. Oligosarcus, reproduction, Characidae, southern Brazil.

\section{INTRODUÇÃO}

Oligosarcus jenynsii (Günther, 1864) e O. robustus Menezes, 1969, popularmente conhecidas por branca, tambicu ou peixe-cachorro, são caracídeos encontrados em corpos d'água da planície costeira do sul do Brasil, Uruguai e Argentina; abundantes na lagoa Fortaleza, litoral norte do Rio Grande do Sul, são alvo de pesca amadorística e de subsistência.

Segundo Menezes (1969), Haro \& GutiérRez (1985) e HARTZ et al. (1996), O. jenynsii possui hábito alimentar carnívoro tendendo à piscivoria. Este hábito alimentar ocorre em outra espécie do gênero, $O$. longirostris Menezes \& Gèry, 1983 (Gealh \& Hahn, 1998). Oligosarcus jenynsii foi estudada quanto a sua reprodução por IwASZKIw et al. (1983) em um reservatório em Córdoba, Argentina, por HARTz et al. (1997) na lagoa Caconde, lagoa isolada pertencente à mesma bacia hidrográfica da lagoa Fortaleza (bacia do rio Tramandaí, Rio Grande do Sul), e por FialHo et al. (1998) em lagoa de influência salina nesta mesma bacia hidrográfica (lagoa das Custódias). Nesses trabalhos foram verificadas épocas de reprodução, tipo de desova, fecundidade, proporção sexual e tamanho de primeira maturação gonadal. Em sua síntese sobre reprodução dos Characiformes, VAZZOLER \& Menezes (1992) incluem $O$. jenynsii no grupo de espécies não-migratórias com fertilização externa que não possuem cuidado parental.

Objetiva-se estabelecer o período reprodutivo, tipo de desova, época de recrutamento, proporção sexual, fecundidade absoluta e relativa, bem como tamanho de primeira maturação gonadal, de $O$. jenynsii e $O$. robustus da lagoa Fortaleza.

\section{MATERIAL E MÉTODOS}

A lagoa Fortaleza localiza-se no município de Cidreira, Rio Grande do Sul, fazendo parte do subsistema Tramandaí-Sul (WürdIG, 1987), entre as lagoas Manuel Nunes e Cidreira ( $\left.30^{\circ} 08^{\prime} \mathrm{S}, 50^{\circ} 13^{\prime} \mathrm{W}\right)$. É o quinto corpo lagunar posicionado ao sul do estuário de Tramandaí, possuindo $18,54 \mathrm{~km}^{2}$ de área e $1,74 \mathrm{~m}$ de profundidade média (Schwarzbold \& Schäfer, 1984). Quando comparada a outros corpos d'água da região, é considerada uma lagoa de média superfície e pequena profundidade (SCHÄFER, 1988).

Os exemplares foram coletados mensalmente, de maio de 2000 a abril de 2001, utilizando-se três conjuntos de redes de espera de $120 \mathrm{~m}$ de comprimento por $1,5 \mathrm{~m}$ de altura e malhas de $15 \mathrm{~mm}$ a $40 \mathrm{~mm}$ entre nós adjacentes, a cada $20 \mathrm{~m}$. O esforço de pesca foi de $24 \mathrm{~h} / \mathrm{mês}$, com três períodos de despesca: nascer do sol, meio dia e pôr do sol, e três arrastos/mês com rede do tipo picaré de $30 \mathrm{~m}$ e malha $5 \mathrm{~mm}$, em áreas distintas na lagoa. De cada indivíduo foram tomadas medidas de comprimento total em milímetros, peso total e peso da gônada em gramas e identificados o sexo e os estádios de maturação gonadal. A identificação dos estádios de desenvolvimento gonadal levou em consideração os aspectos macroscópicos das gônadas (NiKolsky, 1963), observando-se a coloração, vascularização, tamanho relativo à cavidade abdominal e flacidez, sendo 
reconhecidos os seguintes estádios: imaturo, em maturação, maduro, semi-esgotado e esgotado. Os resultados foram agrupados por bimestres devido ao baixo número amostral em alguns meses.

O período reprodutivo (época de intensa maturação gonadal e conseqüente desova) foi estabelecido segundo SANTOS (1978), mediante as distribuições bimestrais das freqüências relativas de cada estádio de maturação gonadal, da variação bimestral dos valores médios do índice gonadossomático (IGS). Este índice foi calculado como o percentual do peso das gônadas em relação ao peso total do corpo e avaliado bimestralmente através de análise de variância e posterior teste de Tukey (ZAR, 1996). Anteriormente ao cálculo do IGS, os pesos das gônadas foram correlacionados ao peso total para cada sexo e estádio de maturação gonadal, a fim de verificar a significância da relação linear entre estas duas variáveis (De Vlaming et al., 1982). A época de recrutamento, definida aqui como o período em que os indivíduos que nascem em um dado evento reprodutivo começam a ser capturados pelos aparelhos de pesca, baseou-se na distribuição das frequiências relativas de jovens e adultos durante os bimestres de amostragem. Aos valores das proporções sexuais, estimados através das freqüências de machos e fêmeas capturados durante todo o período de amostragem, aplicou-se o teste $\mathrm{x}^{2}(\alpha=0,05)$ para verificar a existência ou não de diferenças significativas, assumindo que o esperado fosse de 1:1.

Para a estimativa da fecundidade, foram selecionadas 10 gônadas de fêmeas maduras de $O$. jenynsii e 26 de $O$. robustus. Estas gônadas foram fixadas em solução de Gilson (VAzZOLER, 1996), visando o total desprendimento dos ovócitos do tecido conjuntivo, e lavadas e conservadas em álcool $70 \%$. Para a contagem dos ovócitos foi utilizada uma pipeta de Stempel ( $5 \mathrm{ml})$, estimando-se assim a fecundidade absoluta $(\mathrm{F})$ através da equação $\mathrm{N}=(\mathrm{n} . \mathrm{V}) / \mathrm{v}$, onde $\mathrm{N}$ é o número total de ovócitos; n é o número médio de ovócitos vitelinados obtidos nas subamostragens (3 réplicas); V é o volume total da solução $(300 \mathrm{ml})$ e v o volume da subamostra (5 $\mathrm{ml}$ ). A fecundidade absoluta foi definida como o número de ovócitos a ser liberado por cada fêmea durante a desova. Para a fecundidade relativa foram estabelecidas relações entre a fecundidade absoluta e as variáveis biométricas comprimento total, peso total e peso das gônadas, através do método dos mínimos quadrados, ou menor variância residual (ZAR, 1996).

Para estimar o tamanho da primeira maturação gonadal, foram obtidas as distribuições das freqüências relativas de adultos (indivíduos com gônadas em maturação, madura, semi-esgotada e esgotada) por classes de comprimento total de $20 \mathrm{~mm}$. Os jovens, capturados com picaré, incluídos na distribuição, não foram separados por sexo, pois esta identificação tornouse inviável devido ao tamanho gonadal bastante pequeno dos exemplares. SANTOS (1978) define tamanho de primeira maturação gonadal como aquele correspondente à classe com $50 \%$ dos indivíduos adultos.

Foram registradas, para cada amostragem, medidas de temperatura $\left({ }^{\circ} \mathrm{C}\right)$ e condutividade da água $\left(\mu \mathrm{S} . \mathrm{cm}^{-1}\right)$ para a discussão da influência de tais parâmetros na reprodução das espécies estudadas.

\section{RESULTADOS}

Foram capturados 152 indivíduos de $O$. jenynsii, dentre estes 9 jovens com comprimento total entre 63 e 112 mm, 51 machos (113 e 210 mm) e 92 fêmeas (115 e 243 $\mathrm{mm})$ e 439 indivíduos de $O$. robustus, sendo 34 jovens (54 e $120 \mathrm{~mm}$ ), 193 machos (121 e $242 \mathrm{~mm}$ ) e 212 fêmeas (124 e $297 \mathrm{~mm})$.

Os coeficientes das regressões lineares entre o peso das gônadas e o peso total (tab. I) validam o uso do IGS, uma vez que quando se dá a relação linear pela origem $(\alpha=0,05)$ do peso da gônada em relação ao peso total, o desenvolvimento gonadal pode ser expresso por este índice.

As duas espécies iniciam a reprodução no bimestre jul/ago, com os maiores valores de IGS, e encerram nos bimestres nov/dez com o final do período de desova (fig. 1). A análise de variância revelou diferenças significativas entre os valores médios bimestrais do índice gonadossomático, tanto para machos quanto para fêmeas de O. jenynsii $\left(\mathrm{F}_{\text {calc }}=283,40\right.$ e 25,79, respectivamente; $\mathrm{P}<0,001)$. O teste de Tukey não revelou diferenças significativas nos valores de IGS para fêmeas de $O$. jenynsii entre os dois primeiros bimestres do início do período reprodutivo. Para os machos houve diferença significativa para tais valores neste período. Os valores de maturação gonadal (início do período reprodutivo) diferiram estatisticamente dos valores obtidos nos

Tabela I. Resultados das regressões lineares (Wt=b.wg) entre o peso das gônadas (wg) e o peso total (Wt) para cada estádio de maturação gonadal em Oligosarcus jenynsii e O. robustus na lagoa Fortaleza, Rio Grande do Sul, maio de 2000 a abril de 2001 (b, coeficiente de regressão; r, coeficiente de correlação linear ( $\alpha=0,05$ de significância); $\mathrm{N}$, número de indivíduos; Emat, em maturação; Mad, maduro; Sesg, semi-esgotado; Esg, esgotado).

\begin{tabular}{|c|c|c|c|c|c|c|c|c|c|}
\hline \multicolumn{5}{|c|}{ O. jenynsii } & \multicolumn{5}{|c|}{ O. robustus } \\
\hline Estádios & $\mathrm{b}$ & Machos & $\mathrm{r}$ & $\mathrm{N}$ & Estádios & $\mathrm{b}$ & Machos & $\mathrm{r}$ & $\mathrm{N}$ \\
\hline Emat & 0,0106 & & 0,93 & 12 & Emat & 0,0095 & & 0,91 & 8 \\
\hline Mad & 0,0253 & & 0,79 & 8 & Mad & 0,0223 & & 0,84 & 18 \\
\hline Sesg & 0,0155 & & 0,87 & 18 & Sesg & 0,0138 & & 0,84 & 109 \\
\hline Esg & 0,0066 & & 0,90 & 7 & Esg & 0,0074 & & 0,87 & 21 \\
\hline Estádios & & Fêmeas & & & Estádios & & Fêmeas & & \\
\hline Emat & 0,0422 & & 0,84 & 26 & Emat & 0,0644 & & 0,88 & 36 \\
\hline Mad & 0,1138 & & 0,97 & 19 & Mad & 0,1130 & & 0,91 & 57 \\
\hline Sesg & 0,0640 & & 0,92 & 20 & Sesg & 0,0672 & & 0,84 & 48 \\
\hline Esg & 0,0100 & & 0,67 & 23 & Esg & 0,0204 & & 0,74 & 54 \\
\hline
\end{tabular}


Oligosarcus jenynsii - Machos

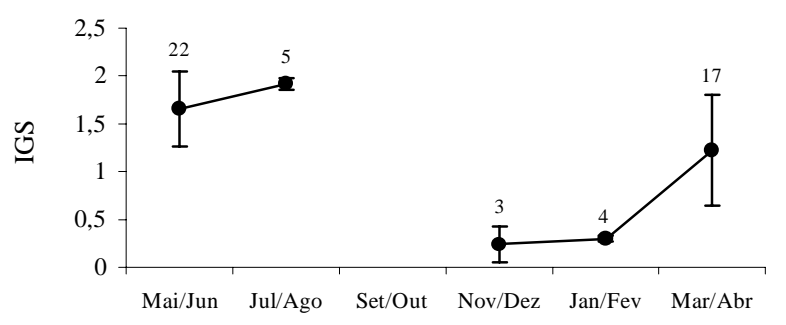

Oligosarcus jenynsii - Fêmeas

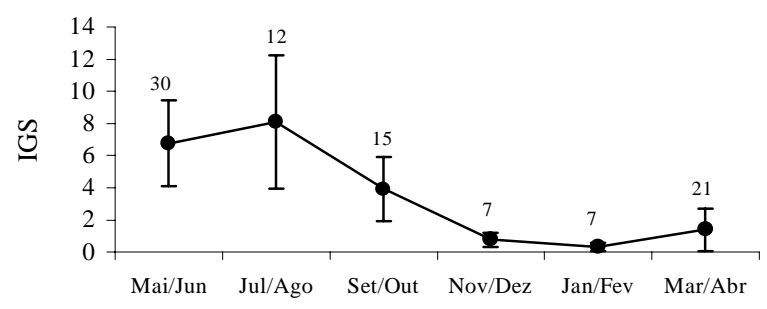

Oligosarcus robustus - Machos

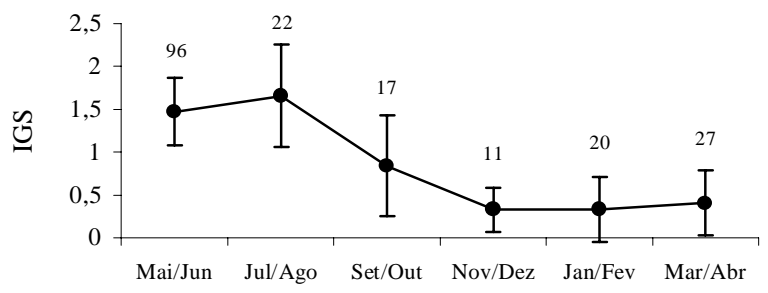

Oligosarcus robustus - Fêmeas

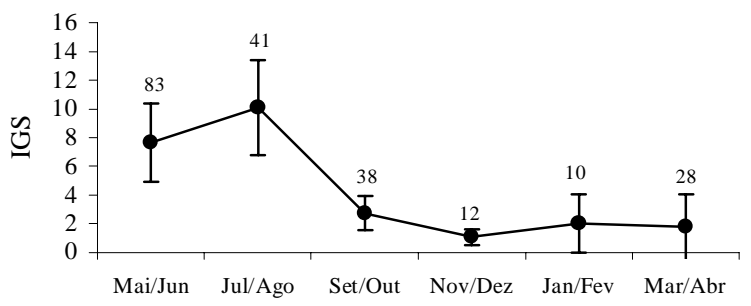

Fig. 1. Variação bimestral dos valores médios do índice gonadossomático (IGS) para machos e fêmeas de Oligosarcus jenynsii e de O. robustus da lagoa Fortaleza, maio de 2000 a abril de 2001. As barras verticais correspondem ao desvio padrão e os números acima, ao total de indivíduos capturados em cada bimestre.

bimestres de esgotamento (final do período reprodutivo), indicando sazonalidade na reprodução. Para $O$. robustus, a análise de variância revelou diferenças significativas entre os valores médios bimestrais do IGS, para machos e fêmeas ( $\mathrm{F}=57,13$ e 72,41, $\mathrm{P}<0,001$, respectivamente). $\mathrm{O}$ teste de Tukey revelou diferenças significativas nos valores do IGS entre os bimestres do início e final do período reprodutivo.

A variação bimestral das freqüências relativas dos estádios de maturação gonadal, das duas espécies (fig. 2), indicou predomínio do estádio maduro no bimestre jul/ago. O estádio esgotado apresentou aumento de frequiência no bimestre set/out, estendendo-se até nov/ dez e jan/fev, indicando que a desova ocorreu durante este período do ano. A distribuição bimestral das freqüências relativas de exemplares jovens e adultos (fig. 3 ) permite verificar que, para $O$. robustus, o período de recrutamento se estende até o bimestre mar/abr e o de $O$. jenynsii praticamente ocorre no bimestre jan/fev.

Considerando-se o total de indivíduos capturados no período amostral, a proporção sexual diferiu significativamente de $1: 1\left(\mathrm{x}^{2}=11,755 ; \alpha=0,05\right) \mathrm{em}$ Oligosarcus jenynsii. $\mathrm{Na}$ distribuição bimestral das freqüências relativas de machos e fêmeas desta espécie (fig.3), verifica-se que as fêmeas são mais numerosas em todos os bimestres em uma proporção aproximada de 2:1. Para $O$. robustus não houve diferenças significativas $\left(\mathrm{x}^{2}=\right.$ $0,891, \alpha=0,05)$, apresentando uma proporção sexual semelhante a 1:1 com a distribuição das frequiências relativas de machos e fêmeas praticamente semelhante em todos os bimestres (fig. 3).

A fecundidade absoluta média calculada foi de 14483 ovócitos para $O$. jenynsii, com mínimo e máximo de 4620 e 28699 ovócitos vitelinados de fêmeas com comprimento total variando, respectivamente, entre 155 $\mathrm{mm}$ e $243 \mathrm{~mm}$. Oligosarcus robustus apresentou fecundidade absoluta média de 16308 ovócitos, com mínimo de 6900 e máximo de 40219 ovócitos vitelinados de fêmeas medindo entre $199 \mathrm{~mm}$ e $271 \mathrm{~mm}$. As diferenças entre os valores médios da fecundidade absoluta entre as duas espécies não foram significativas $\left(\mathrm{F}_{\text {calc }}=0,532\right.$; $\mathrm{P}<0,001)$. O número total de ovócitos vitelinados produzidos pelas fêmeas em uma estação de desova foi relacionado com o comprimento total, peso total e peso das gônadas para as duas espécies (fig. 4). Estas relações foram positivas para ambas espécies. Em O. jenynsii a fecundidade aumenta potencialmente com o comprimento total e linearmente com o peso total e peso das gônadas; em $O$. robustus a fecundidade aumenta potencialmente com o comprimento total, peso total e com o peso das gônadas.

O tamanho de primeira maturação gonadal estimado para $O$. jenynsii foi registrado na classe de comprimento total entre $84 \mathrm{~mm}$ e $104 \mathrm{~mm}$ para machos e fêmeas (fig. 5). Oligosarcus robustus tem seu tamanho de primeira maturação gonadal na classe de comprimento total entre 126 mm e $146 \mathrm{~mm}$ para ambos os sexos (fig. 5). Durante a realização das amostragens, registrou-se o aumento da temperatura da água entre os bimestres jul/ago e nov/ dez, e a diminuição da condutividade neste mesmo período (fig. 6). 

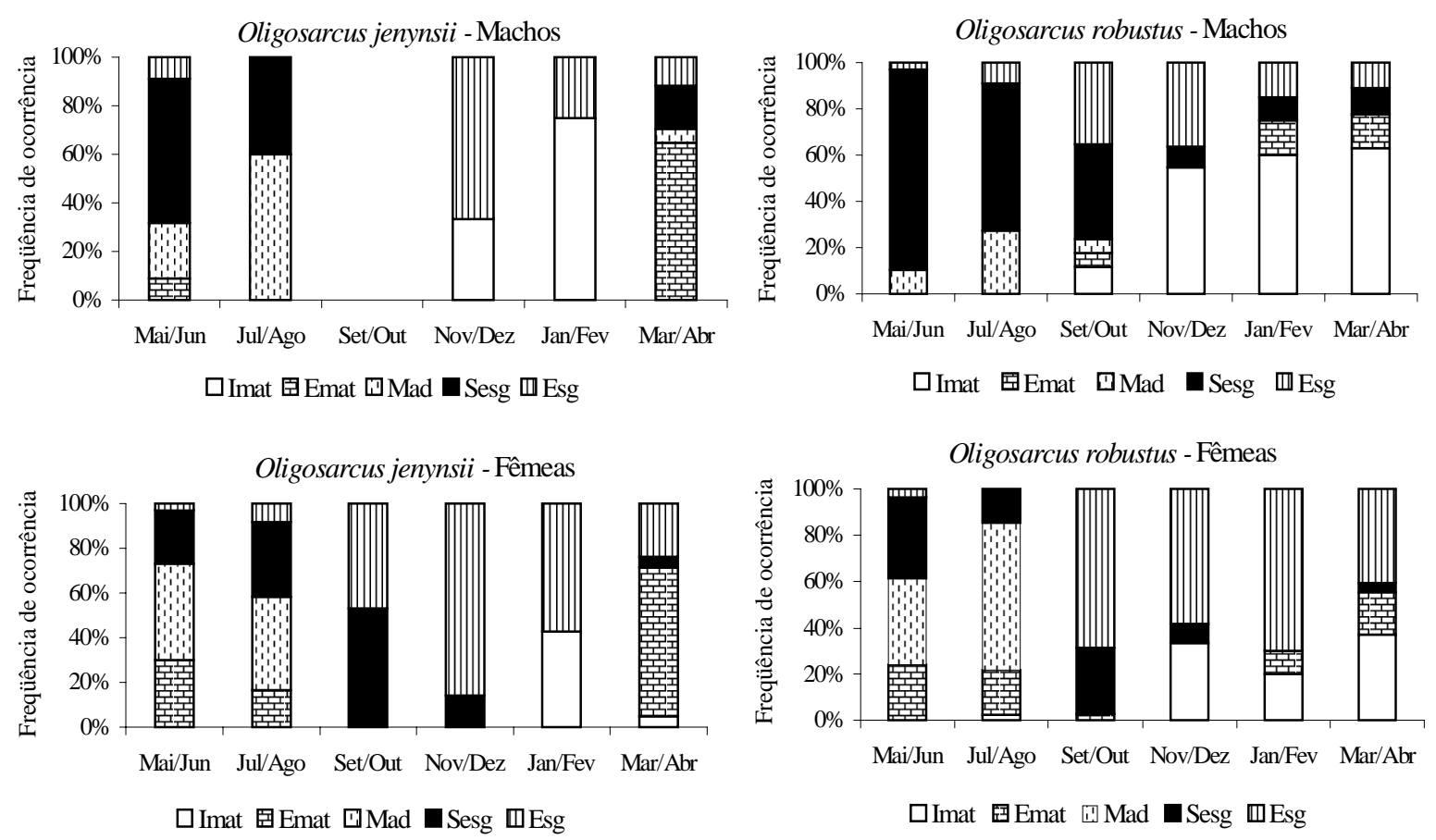

Fig. 2. Distribuição bimestral das freqüências relativas dos estádios de maturação gonadal para machos e fêmeas de Oligosarcus jenynsii e O. robustus, lagoa Fortaleza, maio 2000 a abril 2001 (Imat, imaturo; Emat, em maturação; Mad, maduro; Sesg, semi-esgotado e Esg, esgotado).
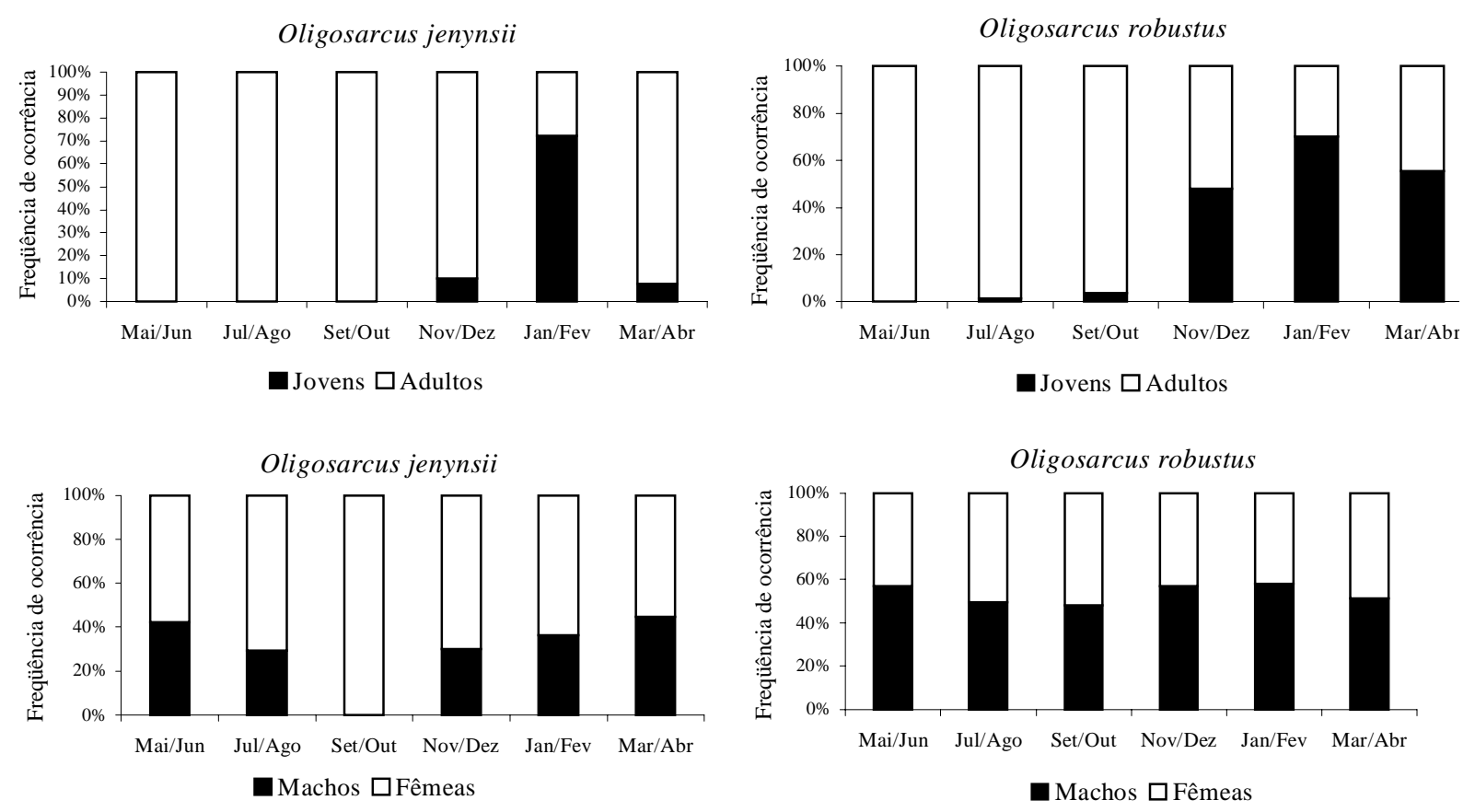

Fig. 3. Distribuição bimestral das freqüências relativas de jovens e adultos e de machos e fêmeas de Oligosarcus jenynsii e $O$. robustus da lagoa Fortaleza, maio 2000 a abril 2001. 

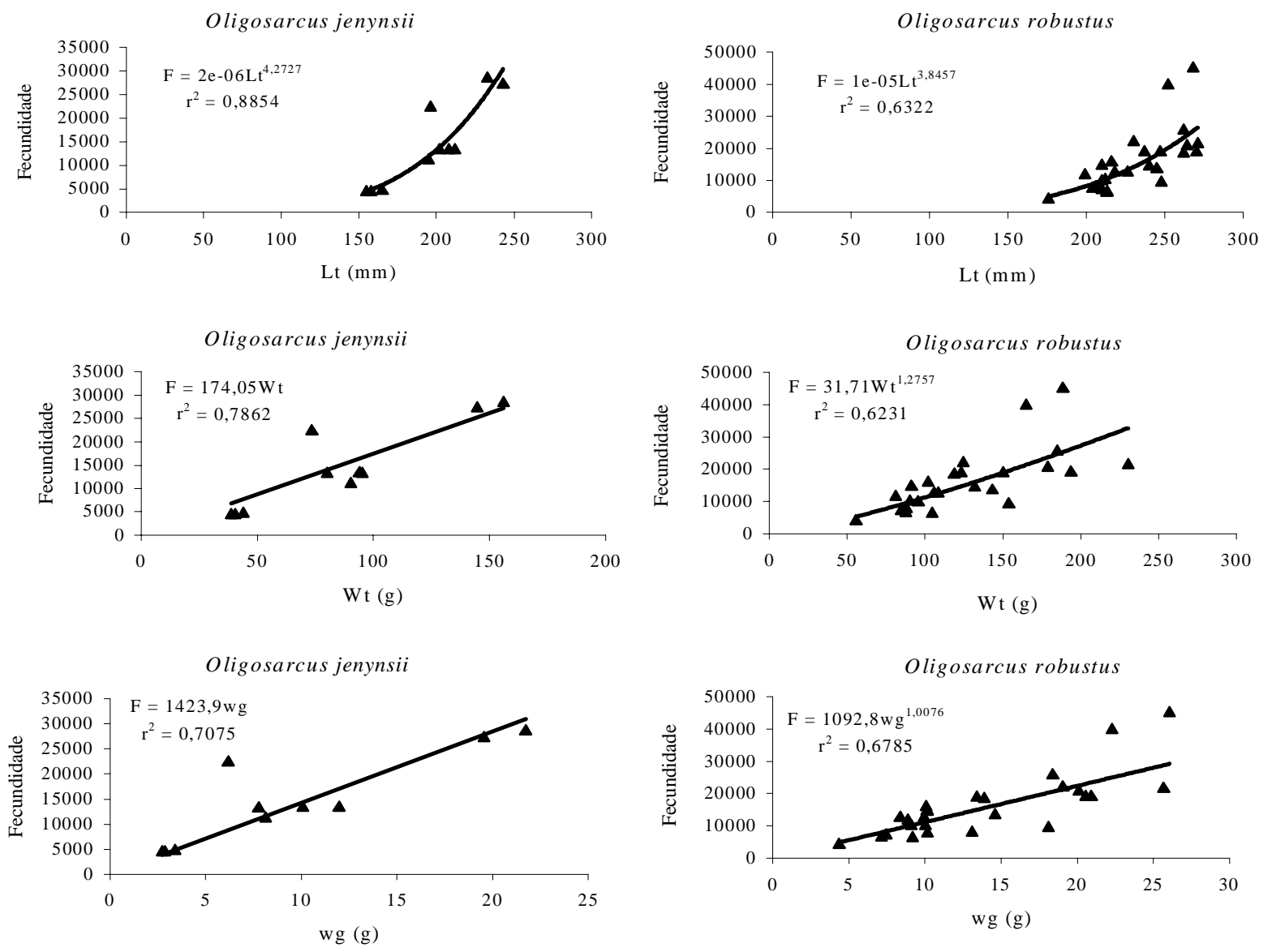

Fig. 4. Relações entre a fecundidade absoluta e o comprimento total (Lt), peso total (Wt) e peso das gônadas (wg) para fêmeas de Oligosarcus jenynsii e O. robustus, lagoa Fortaleza, maio 2000 a abril 2001.
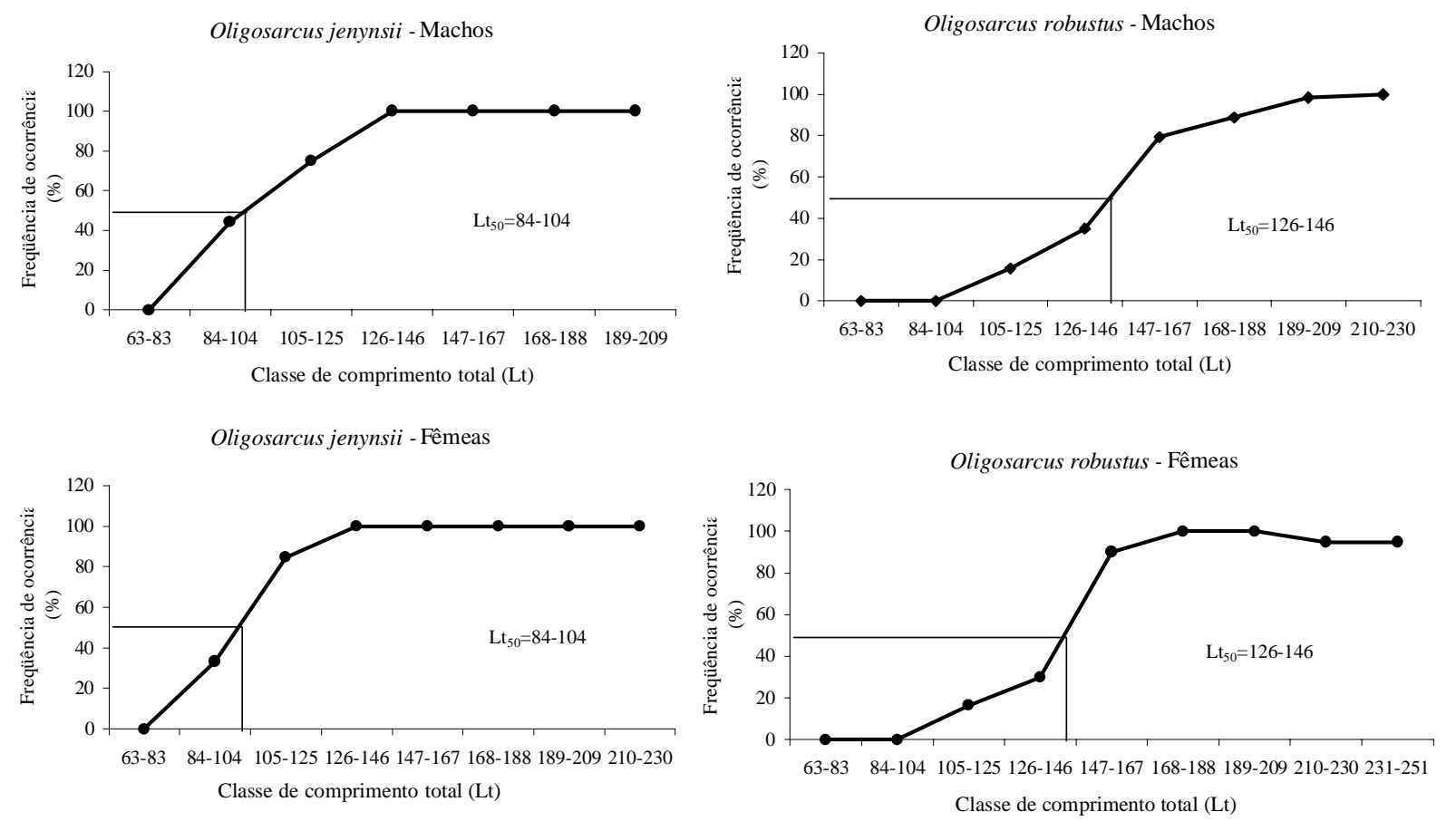

Fig. 5. Relação entre a freqüência de indivíduos adultos e as classes de comprimento total (Lt) para machos e fêmeas de Oligosarcus jenynsii e $O$. robustus, lagoa Fortaleza, maio 2000 a abril 2001. 


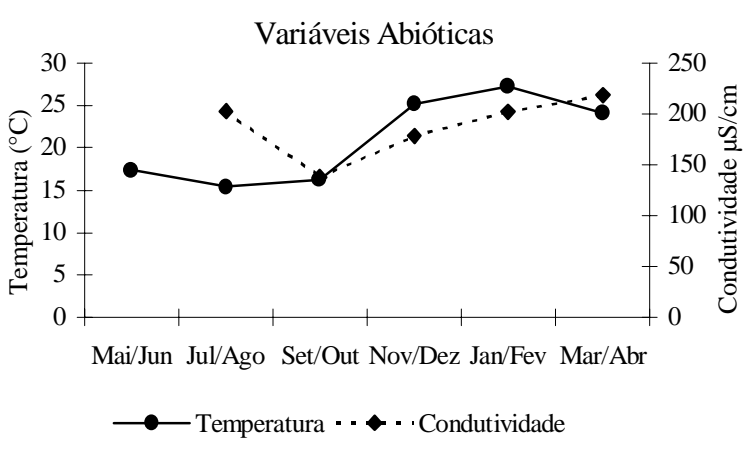

Fig. 6. Valores médios de temperatura e condutividade da água, na lagoa Fortaleza maio 2000 a abril 2001.

\section{DISCUSSÃO}

A freqüência de captura de $O$. robustus foi maior que a de $O$. jenynsii, bem como o tamanho dos indivíduos amostrados. Este resultado pode não indicar relações de abundância entre as espécies na lagoa. Oligosarcus robustus, por ter maior porte, pode ter apresentado maior suscetibilidade à captura.

As fêmeas das duas espécies apresentaram tamanho maior que os machos. Este dimorfismo sexual está diretamente relacionado com a produção de ovócitos; estes peixes fazem parte de um grupo de espécies cuja fecundidade aumenta numa razão direta com o tamanho corpóreo. A fecundidade relativa expressa o número de ovócitos em relação ao peso ou comprimento. Segundo WootTon (1991), a relação típica entre estas variáveis é potencial. Em $O$. jenynsii da lagoa Fortaleza, as relações observadas com o comprimento total, peso total e peso das gônadas foram potencial e linear, respectivamente, assim como as encontradas por Fialho et al. (1998) para O. jenynsii da lagoa das Custódias e Hartz et al. (1997) na lagoa Caconde. IwaszKiw et al. (1983), estudando $O$. jenynsii na Argentina, demonstraram uma relação potencial entre o comprimento e o peso total, e linear entre fecundidade e peso das gônadas. As diferenças ambientais quanto à temperatura e quantidade de alimento, por exemplo, podem estar influenciando na longevidade e no tamanho dos exemplares, levando a alterações nas relações entre as variáveis nos diferentes ambientes.

A maior correlação ocorreu entre as variáveis de fecundidade e comprimento total para $O$. jenynsii, diferindo do encontrado por HARTZ et al. (1997) na lagoa Caconde, onde o maior coeficiente de correlação se deu entre fecundidade e peso das gônadas, sendo o mesmo resultado encontrado para $O$. robustus da lagoa Fortaleza. BAGENAL (1957) considerou o comprimento total o melhor indicador da fecundidade, uma vez que este parâmetro não varia em uma mesma estação reprodutiva, diferentemente do peso, que pode assumir valores maiores ou menores, de acordo com as condições ambientais. As fecundidades absolutas médias de $O$. jenynsii e de $O$. robustus não diferem significativamente entre si. Oligosarcus robustus da lagoa Fortaleza parece apresentar o mesmo tipo de desova que $O$. jenynsii (parcelada), ainda que por um período mais longo.
Segundo NiKolsky (1969), a fecundidade em espécies de peixes pode variar de uma estação reprodutiva para outra por causa das dependências de condições alimentares, longevidade e tamanho de primeira maturação gonadal.

A fecundidade média encontrada por fêmea madura de $O$. jenynsii da lagoa Fortaleza está mais próxima à encontrada na lagoa Caconde por HARTZ et al. (1997), que estimaram 17684 ovócitos para a espécie. Para FialHo et al. (1998), o valor de fecundidade absoluta média apresentado para $O$. jenynsii foi de 9694 ovócitos. Apesar de não terem sido testadas as diferenças estatísticas entre O. jenynsii da lagoa Fortaleza e da lagoa das Custódias, esta baixa fecundidade em relação à mesma espécie pode estar relacionada ao ambiente estuarino das Custódias, onde as espécies precisam se ajustar às diferenças de salinidade, provocando uma demanda de energia para manutenção corpórea maior que o normal, podendo reduzir o peso e o tamanho dos indivíduos bem como o número de ovócitos produzidos. Quando comparada com outras espécies de Characiformes (VAzzoler \& Menezes, 1992), O. jenynsii pode ser incluída na categoria de espécies de fecundidade intermediária, entre a baixa fecundidade de outras espécies como Hoplias malabaricus (Bloch, 1794), a traíra, que apresenta cuidados parentais, e a alta fecundidade de Salminus maxillosus Valenciennes, 1849, o dourado, com migração reprodutiva. A época reprodutiva estabelecida para $O$. jenynsii, entre os bimestres jul/ago a nov/dez, foi a mesma encontrada por HaRTZ et al. (1997) e por FialHo et al. (1998) em outras lagoas da região.

As frequiências relativas dos estádios de maturação gonadal de $O$. jenynsii da lagoa Fortaleza revelam que as fêmeas começam a maturar um pouco antes dos machos, diferença que não ocorre em $O$. robustus, sendo que estas duas espécies desovam no final do inverno, com o aumento das chuvas e início da elevação da temperatura da água. A época de recrutamento corrobora este resultado, com a maior frequiência de indivíduos jovens no período que procede a desova (época de verão e outono). No Paraná, Oligosarcus longirostris Menezes \& Gèry, 1983 desova nos meses de verão (GEALH \& HAHN, 1998). A época de desova está relacionada com um aumento da temperatura da água e um período de maior pluviosidade, parecendo ser este o parâmetro mais significativo para a desova das espécies. A queda nos valores médios de condutividade na lagoa Fortaleza, no bimestre set/out, está relacionada com um período de maior precipitação, ocasionando maior diluição dos íons na água. Segundo Hasenack \& Ferraro (1989), as precipitações na região desta lagoa são freqüentes na primavera e verão. Provavelmente a desova esteja ocorrendo no início do período quente para que as larvas possam ter maior abundância alimentar, e condições de temperatura favoráveis ao seu desenvolvimento, sendo este período identificado através do aumento da precipitação. Para Cyphocharax voga (Hensel, 1869), estudada na mesma bacia hidrográfica (lagoa Emboaba), HARTZ \& BARBIERI (1994) encontraram comportamento de desova diferenciado em um ano chuvoso, atribuindo maior importância a este fator para a desova da espécie.

Em caracídeos geralmente é comum uma maior captura de fêmeas (HARTz et al., 1997). Na lagoa Fortaleza também se verificou maior proporção de fêmeas de $O$. jenynsii em todos 
os bimestres, principalmente no período de desova, quando não foi capturado nenhum macho, o mesmo não ocorrendo com O. robustus. Segundo RickLEFs (1990), a simples obrigação de encontrar um lugar conveniente para desovar pode exigir das fêmeas a utilização de hábitats diferentes dos machos durante o período de desova, ocasionando assim maior atividade de cardumes específicos neste período. As diferenças nas proporções corpóreas entre os sexos, levando as fêmeas a apresentarem tamanho corpóreo maior, podem ocasionar maior probabilidade de captura pelos aparelhos de pesca. HARTZ \& BARBIERI (1995) encontraram crescimento diferenciado entre os sexos de $O$. jenynsii na lagoa Caconde, obtendo também maior proporção de fêmeas em relação aos machos. Em relação a $O$. robustus, não se conhece o fato desta espécie apresentar crescimento diferenciado entre os sexos, provavelmente isto não acontece, visto a mesma proporção de machos e fêmeas capturados na lagoa da Fortaleza. As proporções sexuais diferenciadas na lagoa Fortaleza sugerem estratégias reprodutivas diferenciadas entre as espécies, tais como comportamento de corte, locais de desova e existência de cardumes específicos.

Para machos e fêmeas de $O$. jenynsii da lagoa Fortaleza, a classe de comprimento total de primeira maturação diferiu (cerca de $10 \mathrm{~mm}$ menor) do encontrado por FialHo et al. (1998) para $O$. jenynsii da lagoa das Custódias, que foi de 114 mm para machos e $131 \mathrm{~mm}$ para fêmeas. HARTZ et al. (1997), estudando $O$. jenynsii na lagoa Caconde, encontraram tamanho de primeira maturação gonadal igual a $117 \mathrm{~mm}$ para machos e $136 \mathrm{~mm}$ para fêmeas. Iwaszkiw et al. (1983) registraram para $O$. jenynsii, tamanho de primeira maturação para fêmeas de $145 \mathrm{~mm}$, aproximadamente. Não foram realizadas análises para verificar se estas diferenças entre o comprimento total de primeira maturação de $O$. jenynsii dos três ambientes discutidos, sempre maiores do que os encontrados para a espécie na lagoa Fortaleza, referem-se de fato a indivíduos de mesma idade, provavelmente estes valores representam indivíduos de idades semelhantes. Para machos e fêmeas de $O$. robustus, o tamanho de primeira maturação gonadal foi entre as classes de comprimento total de $126 \mathrm{~mm}$ e $146 \mathrm{~mm}$, indicando que machos e fêmeas de $O$. robustus maturam na mesma idade.

Os resultados demonstram não haver diferenças significativas nos parâmetros reprodutivos estudados das duas espécies. Não se descarta a possibilidade de indivíduos híbridos, visto que as espécies se reproduzem na mesma época e são capturadas juntas em redes de emalhar e picaré.

Agradecimentos. À FAPERGS, pelo financiamento (processo $n^{\circ}$ 00/0840-1); à CAPES, pela concessão de bolsa de mestrado para a primeira autora; ao Centro de Ecologia/UFRGS, pelo auxílio logístico; ao CECLIMAR/UFRGS, pelo auxílio de pessoal. Aos pesquisadores Fernando G. Becker (Fundação Zoobotânica, RS), Nelson Fontoura (Pontifícia Universidade Católica, RS), Willi Bruschi Jr. (Biolaw Consultoria Ambiental, Porto Alegre) e Geraldo Barbieri (Instituto de Pesca, São Paulo) pela leitura crítica do manuscrito.

\section{REFERÊNCIAS BIBLIOGRÁFICAS}

Bagenal, T. B. 1957. Annual variations in fish fecundity. Journal of the Marine Biological Association of the United Kingdom, Hoods Wole, 36:377-382.
De Vlaming, V.; Grossman, G. \& Chapman, F. 1982. On the use of the gonosomatic index. Comparative Biochemistry and Physiology, Southampton, 73:31-39.

Fialho, C. B.; Schifino, L. C. \& Verani, J. R. 1998. Biologia reprodutiva de Oligosarcus jenynsii (Günther) (Characiformes, Characidae) da lagoa das Custódias, Tramandaí, Rio Grande do Sul, Brasil. Revista Brasileira de Zoologia, Curitiba, 15(3):775-782.

Gealh, A. M. \& Hahn, N. S. 1998. Alimentação de Oligosarcus longirostris Menezes \& Gèry (Osteichthyes, Acestrorhynchinae) do Reservatório de Salto Segredo, Paraná, Brasil. Revista Brasileira de Zoologia, Curitiba, 15(4):985993.

Haro, J. G. \& Gutiérrez, M. 1985. Alimentación de Oligosarcus jenynsii (Günther, 1864) (Pisces, Characidae) en el Lago San Roque (Cordoba, Argentina). Revista de la Asocciación de Ciencias Naturales del Litoral, Santo Tomé, 16(2):227-235.

HartZ, S. M. \& Barbieri, G. 1994. Dinâmica da reprodução de Cyphocharax voga (Hensel, 1869) da lagoa Emboaba, RS, Brasil (Characiformes, Curimatidae). Revista Brasileira de Biologia, Rio de Janeiro, 54(3):459-468.

1995. Crescimento do peixe-cachorro, Oligosarcus jenynsii (Günther, 1864), na lagoa Caconde, Rio Grande do Sul, Brasil (Teleostei, Characidae). Boletim do Instituto de Pesca, São Paulo, 22(2):33-40.

Hartz, S. M.; Martins, A. \& Barbieri, G. 1996. Dinâmica da alimentação e dieta de Oligosarcus jenynsii (Günther, 1864) na lagoa Caconde, Rio Grande do Sul, Brasil (Teleostei, Characidae). Boletim do Instituto de Pesca, São Paulo, 23:21-29.

Hartz, S. M.; Vilella, F. S. \& Barbieri, G. 1997. Reproduction dynamics of Oligosarcus jenynsii (Characiformes, Characidae) in Lake Caconde, Rio Grande do Sul, Brasil. Revista Brasileira de Biologia, Rio de Janeiro, 57(2):295-303.

Hasenack, H. \& Ferraro, L. W. 1989. Considerações sobre o clima da região de Tramandaí, RS. Pesquisas, Porto Alegre, 22:53-70.

Iwaszkiw, J. M.; Freyre, L. R. \& Sendra, E. D. 1983. Estudio de la maduración, epoca de desove y fecundidad del dientudo Oligosarcus jenynsii (Pisces, Characidae) del embalse Río Tercero, Cordoba, Argentina. Limnobios, La Plata, 2(7):518-525.

Menezes, N. A. 1969. The food of Brycon and three closely related genera of the tribe Acestrorhynchini. Papéis Avulsos de Zoologia, São Paulo, 22:217-223.

Niкоlsкy, G. V. 1963. The ecology of fishes. New York, Academic. 352p.

1969. Theory of fish population dynamics. Edinburg, Olivered \& Boid. 323p.

Ricklefs, R. E. 1990. Ecology. New York, W. H. Freeman. 896p. SAntos, E. P. 1978. Dinâmica de populações aplicada à pesca e piscicultura. São Paulo, HUCITEC-EDUSP. 129p.

SCHÄFER, A. 1988. Tipificação ecológica das lagoas costeiras do Rio Grande do Sul, Brasil. Acta Limnologica Brasiliensia, Rio Claro, 2:29-55.

Schwarzbold, A. \& SchäFer, A. 1984. Gênese e morfologia das lagoas costeiras do Rio Grande do Sul, Brasil. Amazoniana, Manaus, 9(1):87-104.

VAzzoler, A. E. A. DE M. 1996. Biologia da reprodução de peixes teleósteos: teoria e prática. Maringá, EDUEM. $169 \mathrm{p}$.

Vazzoler, A. E. A. de M. \& Menezes, N. A. 1992. Síntese de conhecimentos sobre o comportamento reprodutivo dos Characiformes da América do Sul (Teleostei, Ostariophysi). Revista Brasileira de Biologia, Rio de Janeiro, 52(4):627640 .

Wootton, R. J. 1991. Ecology of teleost fishes. London, Chapman \& Hall. 404p.

WÜRDIG, N. L. 1987. Alguns dados físicos e químicos do sistema lagunar de Tramandaí, RS. Pesquisas, Porto Alegre, 20:49-74.

ZaR, J. H. 1996. Biostatistical analysis. New Jersey, PrenticeHall. 620p.

Recebido em junho de 2002. Aceito em julho de 2003. ISSN 0073-4721 